\title{
Atrial Natriuretic Peptide Protects against Acute Ischemic Renal Failure in the Rat
}

Sidney G. Shaw, Peter Weidmann, Jürg Hodler, Arthur Zimmermann, and Adriano Paternostro

Medizinische Poliklinik and Institute of Pathology, University of Berne, Berne, Switzerland

\begin{abstract}
Because of its ability to increase glomerular filtration, antagonize the actions of vasoconstrictors, and produce vasodilatation, alpha human atrial natriuretic peptide ( $\alpha$-hANP) was evaluated for its potentially beneficial effects in experimental ischemic renal failure induced by $45-60 \mathrm{~min}$ of renal artery occlusion in bilaterally or unilaterally renally intact SpragueDawley rats. After ischemia, a 4-h intrarenal infusion of $\alpha$ hANP restored ${ }^{14} \mathrm{C}$-inulin clearances in bilaterally and unilaterally intact animals from $0.05 \pm 0.006$ and $0.05 \pm 0.01 \mathrm{ml} /$ $\min$ per $100 \mathrm{~g}$ to $0.314 \pm 0.04$ and $0.25 \pm 0.01 \mathrm{ml} / \mathrm{min}$ per $100 \mathrm{~g}$, respectively $(P<0.001, n=8)$, compared with normal values of $0.49 \pm 0.023 \mathrm{ml} / \mathrm{min}$ per $100 \mathrm{~g}$. Histologically, there was a progressive decrease in medullary hyperemia and prevention of intratubular cell shedding and granulocyte margination as a result of the 4-h $\alpha$-hANP infusion such that after 24 and $48 \mathrm{~h}$ the histological appearance of the tissue was essentially normal. The results show that a 4-h intrarenal infusion of $\alpha$-hANP after renal ischemia can preserve glomerular filtration rate and reduce renal tissue damage.
\end{abstract}

\section{Introduction}

Despite the introduction of modern dialysis techniques, a poor prognosis and high risk of mortality still accompany acute renal failure (ARF) ${ }^{1}$ after ischemia or surgical trauma (1). So far no single pharmacological intervention has been shown to reliably prevent the maintained loss of renal function after these events. Recently, however, several peptides that may have therapeutic potential have been isolated from atrial extracts of rodent and human atria. Collectively the peptides have been termed atrial natriuretic peptides (ANP) and share a nearly homologous amino acid sequence at the carboxy terminal end $(2,3)$. Functionally, they have been shown to cause pronounced alternations in renal salt and water excretion, relax precontracted vascular and nonvascular smooth muscle, and increase glomerular filtration rate (4-6). Because acute renal failure secondary to ischemia is frequently seen clinically and is associated with reduced glomerular filtration and intrarenal vasoconstriction, the present study evaluated the ability of the human form of the peptide (the 28-amino acid alpha

Address correspondence to S. G. Shaw, Ph.D., Medizinische Poliklinik, University of Berne, Freiburgstrasse 3, 3010 Berne, Switzerland. 1987.

Received for publication 27 June 1986 and in revised form 2 April

1. Abbreviations used in this paper: ANP, atrial natriuretic peptide; ARF, acute renal failure; $\alpha$-hANP, alpha human ANP.

J. Clin. Invest.

(C) The American Society for Clinical Investigation, Inc. $0021-9738 / 87 / 11 / 1232 / 06 \$ 2.00$

Volume 80, November 1987, 1232-1237 human ANP [ $\alpha$-hANP]) to attenuate the decrement in renal function produced by 60 min of complete unilateral renal artery occlusion in an experimental model of ischemic renal failure in the rat.

\section{Methods}

Uninephrectomized animals. Female Sprague-Dawley rats weighing 280-300 g were used in all experiments. Four groups of six animals, two control and two experimental, were studied for effects of a 4-h intrarenal infusion of either $\alpha$-hANP or vehicle on the severity of renal failure at 4 and $24 \mathrm{~h}$ after $60 \mathrm{~min}$ of renal artery occlusion. Plasma creatinine, endogenous creatinine clearance, fractional sodium excretion, and urine volume were monitored. Plasma and urinary sodium were measured by flame photometer, and creatinine by autoanalyzer (Greiner S. A., Langenthal, Switzerland). All animals were uninephrectomized on the right side and maintained on tap water and a standard pellet diet for 2 wk before implantation, under nembutal anesthesia, of jugular vein and carotid artery cannulae for the infusion of Ringer's solution, blood sampling, and measurement of mean arterial pressure. In control and experimental groups destined for acute nonrecovery experiments, a midline abdominal incision was made, the bladder was cannulated, the urethra was ligated, and the renal artery was dissected at the level of the aorta. The abdominal cavity was flushed with warm Ringer's solution and covered with parafilm. A 30-min equilibration period was then allowed while animals received an intravenous infusion of Ringer's solution at a rate of $1.5 \mathrm{ml} / \mathrm{h}$. At the end of the equilibration period, an initial blood sample was taken for determination of basal creatinine levels and hematocrit, then the renal artery was occluded for $60 \mathrm{~min}$ with a nontraumatizing arterial clamp. Throughout the experiment, an electrically heated blanket maintained the rectal temperature of both control and experimental groups between 34 and $35^{\circ} \mathrm{C}$. Immediately after removal of the arterial clamp, $\alpha$-hANP (Bissendorf Peptide GmbH, Wedemark, FRG) at a calculated concentration of $6.25 \mu \mathrm{g} / \mathrm{ml}$ and dissolved in saline containing 1\% human serum albumin was infused for $4 \mathrm{~h}$ into the renal artery of the experimental group at a rate of $13 \mu \mathrm{l} / \mathrm{min}$. Controls were infused only with saline/albumin at the same rate. Infusion cannulae consisted of a tapered stainless steel hypodermic needle (OD, $0.4 \times 19$ $\mathrm{mm}$ ) that was bent at right angles near the tip so that 1-2 $\mathrm{mm}$ protruded into the renal artery when the needle was inserted at the level of the aorta. Throughout the experiment all animals received an intravenous infusion of Ringer's solution to replace urine losses and maintain average hematocrit readings of $43 \pm 0.5$ vs. $42 \pm 1.4 \%$ at the beginning and end of the experiments, respectively. 1-h urine volumes and final blood samples were collected during and at the end of the final 3-4 h of $\alpha$-hANP infusion. To assess the long term effects of the 4-h $\alpha$-hANP infusion, the same procedure was performed in two separate groups of animals which were then allowed to recover for $24 \mathrm{~h}$ before being placed in metabolic cages for collection of awake 24-h urine samples. In these animals, bladder cannulation and urethral ligation were omitted before clamping and $\alpha$-hANP infusion and the arterial puncture was sealed with cyanoacrylate-impregnated tissue.

For histology, renal tissue slices representing cortex, medulla, and papilla were immersion-fixed in formalin and Bouin's solution immediately after removal from the animals.

Assessment of gross morphology of kidneys. The macroscopic appearance of the freshly cut renal surface and the cut surface after fixation was semiquantitatively assessed (7). In comparison with con- 
trols, the cortex of ischemic kidneys was essentially unchanged and, therefore, the analysis was focused on changes in medulla and papilla. The criteria for allocating a given change to a severity grade are as follows. (O), Normal) No relevant difference in comparison with the control. $(+$, Slight change) Only a small zone of modest hyperemia seen in the outer medulla. $(++$, Moderate change) Moderate degree of hyperemia in the inner medulla extending into the outer medulla. $(+++$, Severe change) Severe hyperemia (with bluish discoloration) of inner medulla, extending into outer medulla and involving the base of the papilla.

Histopathological assessment of renal tissue alterations. For the histopathological assessment of major alterations in kidney structure, representative hemotoxylin-eosin stained sections of plastic-embedded renal tissue were semiquantitatively analyzed. Cortex, medulla, and papilla were represented in each of the sections used.

Parameters used were $(a)$ peritubular hyperemia, defined as an increase of blood content in peritubular capillaries and venules of outer medulla, inner medulla, and papilla, with dilation of the vessels involved, but without hemorrhage, (b) protein casts, defined as dense protein deposits occupying the whole luminal space of a sectioned tubular profile, $(c)$ incipient tubular cell shedding, defined as a disconnection of tubular epithelial cells from their basal lamina, indicative of tubular damage, and $(d)$ granulocyte margination, defined as an intravascular accumulation of neutrophils within the marginal pool, i.e., upon the endothelial lining of the vessels. This is an early leukocyte reaction associated with ongoing tissue damage before neutrophil egress.

In each section, the outer medulla, inner medulla, and base of the papilla were asssessed for the alterations indicated above by testing high power fields continuously aligned along the whole sectioned areas. Between 124 and 154 high-power fields were thus analyzed. Within each high-power field all four parameters were tested on a yes or no base, i.e., irrespective of the number of lesions in a given field with a positive finding. Positive findings for each parameter were then summed and expressed as a percent of the high-power field analyzed.

${ }^{14} \mathrm{C}$-Inulin clearance studies. Because endogenous creatinine clearances may not always accurately reflect impairment of glomerular filtration in acute renal failure and uninephrectomy in itself may partially protect the remaining kidney from ischemic injury, the effect of the $4-\mathrm{h} \alpha$-hANP infusion on the classical clearance of ${ }^{14} \mathrm{C}$-inulin was assessed in a second study of both uninephrectomized $(n=8)$ and bilaterally renally intact animals $(n=12) 4 \mathrm{~h}$ after ischemia. The procedure described above was used for the induction of acute renal failure and intrarenal $\alpha$-hANP infusion, except that in bilaterally renally intact animals the left kidney was clamped for $45(n=8)$ or $60(n$ $=4$ ) $\mathrm{min} .{ }^{14} \mathrm{C}$-Inulin was given during the experiment as a priming intravenous injection of $5 \mu \mathrm{Ci}$ followed by a constant infusion at 3.75 $\mu \mathrm{Ci} / \mathrm{h}$. In all animals, timed urine samples during the final 3-4 $\mathrm{h}$ of $\alpha$-hANP infusion were obtained from previously implanted ureter cannulae. Plasma inulin concentrations were measured at the midpoint of the collection. Glomerular filtration rate was calculated as the urinary clearance of inulin during this collection period, corrected for body weight. To clarify the relationship between ${ }^{14} \mathrm{C}$-inulin clearances and those of endogenous creatinine over a wide range of GFR values, we simultaneously measured each parameter on a series of kidneys which had either normal function $(n=18)$ or mild $(n=17)$ to severe $(n$ $=16) \mathrm{ARF}$ induced by periods of renal ischemia ranging from 15 to $60 \mathrm{~min}$.

Statistics. Differences between $\alpha$-hANP and placebo-treated groups were evaluated using the two-tailed $t$ test for unpaired data. All results are expressed as the mean \pm SEM.

\section{Results}

Occlusion of the renal artery for $60 \mathrm{~min}$ results in a severe form of ischemic $\operatorname{ARF}(8,9)$ which in control uninephrectomized Sprague-Dawley rats (Fig. 1) was manifested by a de-
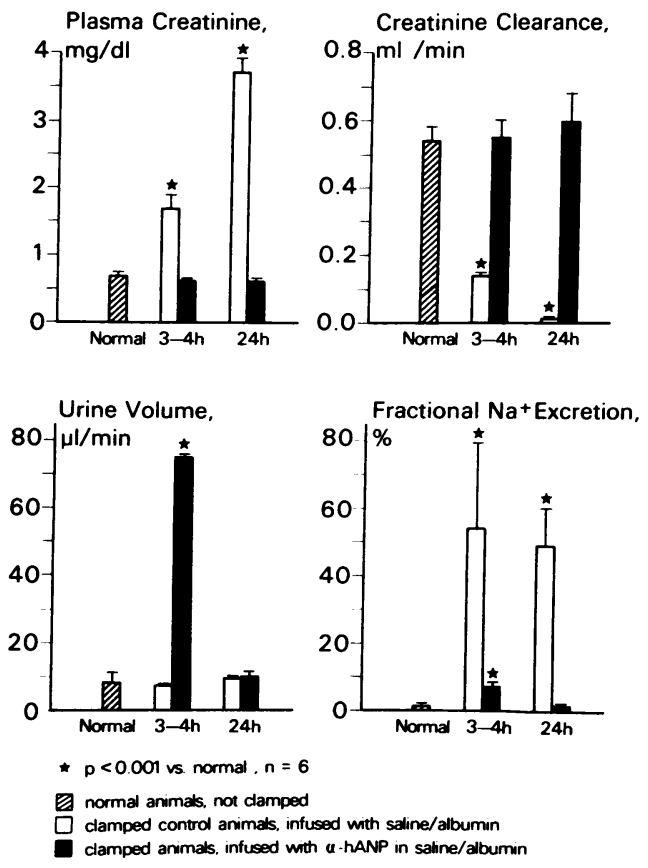

Figure 1. Effects of 4-h infusion of $\alpha$-hANP on plasma creatinine levels, endogenous creatinine clearance, urine volume, and fractional sodium excretion, 3-4 h and $24 \mathrm{~h}$ after $60 \mathrm{~min}$ of renal artery clamping in uninephrectomized rats. Infusion of $\alpha$-hANP restored endogenous creatinine clearances to the normal range and the severe renal failure seen in control animals was avoided. In all groups, $n=6$.

crease in endogenous creatinine clearance from $0.54 \pm 0.04$ $\mathrm{ml} / \mathrm{min}$ in normal animals, to $0.14 \pm 0.01$ at $4 \mathrm{~h}$ and $0.01 \pm 0.004 \mathrm{ml} / \mathrm{min}$ at $24 \mathrm{~h}$ after unclamping. These decreases in creatinine clearance were mirrored by reciprocal increases in plasma creatinine from normal basal levels of $0.7 \pm 0.03$ $\mathrm{mg} / \mathrm{dl}$ to $1.7 \pm 0.2 \mathrm{mg} / \mathrm{dl}$ at $4 \mathrm{~h}$ and $3.7 \pm 0.2 \mathrm{mg} / \mathrm{dl}$ at $24 \mathrm{~h}$. Fractional sodium excretion was similarly elevated from baseline values of $0.68 \pm 0.2 \%$ to $54 \pm 24 \%$ at $4 \mathrm{~h}$ and $49 \pm 11 \%$ at 24 $h$, reflecting tubular damage and impaired reabsorption of sodium.

In contrast, in animals which after removal of the renal artery clamp received an intrarenal infusion of $\alpha$-hANP for 4 $h$, endogenous creatinine clearance rates and plasma creatinine concentrations at 4 and $24 \mathrm{~h}$ after the ischemic insult were restored to the normal range. Urine volume increased 10-fold during $\alpha$-hANP infusion to reach rates of $75 \pm 0.1 \mu \mathrm{l} /$ min compared with $7.2 \pm 0.1 \mu \mathrm{l} / \mathrm{min}$ in saline/albumin-infused controls. Fractional sodium excretion was also increased, reflecting the natriuretic action of the peptide. Classical measurements of glomerular filtration rate using ${ }^{14} \mathrm{C}$-inulin after 4 $\mathrm{h}$ of $\alpha$-hANP infusion in postischemic kidneys again revealed a protective action of the peptide, but in contrast to the clearance of endogenous creatinine, ${ }^{14} \mathrm{C}$-inulin clearance was restored only to $\sim 50 \%$ of normal. Clearance of ${ }^{14} \mathrm{C}$-inulin in nonclamped unilaterally renally intact animals under these conditions averaged $0.49 \pm 0.023 \mathrm{ml} / \mathrm{min}$ per $100 \mathrm{~g}$ body wt $(n$ $=18$ ). This was reduced by $90 \%$ after $60 \mathrm{~min}$ of renal ischemia and a 4-h intrarenal infusion of the saline albumin vehicle to $0.053 \pm 0.006 \mathrm{ml} / \mathrm{min}$ per $100 \mathrm{~g}(n=8)$, whereas $\alpha$-hANP-infused animals had inulin clearances of $0.25 \pm 0.01 \mathrm{ml} / \mathrm{min}$ per $100 \mathrm{~g}(P<0.001, n=8)$. The reason for the apparent difference in renal function measured by endogenous creatinine and 
inulin clearances becomes apparent when simultaneous measurements are compared in kidneys over a range of glomerular filtration rate (GFR) values (Fig. 2). In contrast to GFR values using inulin, measurements of endogenous creatinine clearance did not fall outside the normally measured range until there was marked renal impairment reflected by a decrease in the inulin clearance values to $<0.2 \mathrm{ml} / \mathrm{min}$ per 100 g. This may reflect a progressive increase in tubular secretion of creatinine, similar to that observed in patients with moderate reduction of GFR, which maintains creatinine clearance in a normal or near-normal range and serves to prevent the predicted hyperbolic rise above normal values of the serum creatinine level as the GFR falls to approximately half (10). Whatever the exact mechanism, the results show that the 4-h intrarenal infusion of $\alpha$-hANP after $60 \mathrm{~min}$ of renal ischemia in unilaterally renally intact animals markedly reduces the severe impairment of GFR normally seen in saline/albumin-infused controls at 4 and $24 \mathrm{~h}$ after ischemia to the extent that overt signs of renal failure, reflected by elevations in plasma creatinine and decreases in endogenous creatinine clearance, do not become evident.

Bilaterally renally intact animals. In an initial study using bilaterally renally intact animals $(n=4)$, in which $60 \mathrm{~min}$ of left renal artery clamping was followed by a 4-h intrarenal infusion of $\alpha$-hANP, GFR measured by inulin clearance was not restored after $\alpha$-hANP infusion and averaged $0.04 \pm 0.01$ $\mathrm{ml} / \mathrm{min}$ per $100 \mathrm{~g}$ at $4 \mathrm{~h}$ compared with normal values of $0.5 \pm 0.03 \mathrm{ml} / \mathrm{min}$ per $100 \mathrm{~g}(n=6)$. In these nonresponding animals, hematocrit increased from initial values of $46 \pm 1$ to $53 \pm 1$ and could not be adequately controlled. Because of this,

Endogenous Creatinine Clearance $\mathrm{ml} / \mathrm{min} / 100 \mathrm{~g}$ body weight

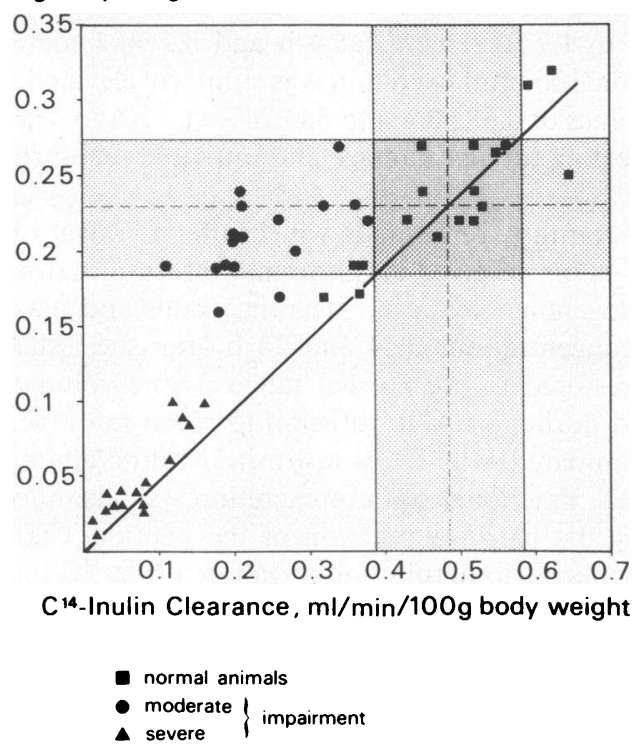

Figure 2. Relationship between simultaneously measured clearances (under nembutal anesthesia) of ${ }^{14} \mathrm{C}$-inulin and endogenous creatinine in kidneys with normal, moderate, and severe renal failure induced by periods of renal ischemia ranging from $15-60 \mathrm{~min}$. Shaded areas show the mean \pm SD of the normally measured values in pentobarbital-anesthetized animals. The diagonal line represents the creatinine/ inulin clearance ratio extrapolated from measurements on normal nonrenally impaired animals. the duration of left-renal-artery clamping was reduced to 45 min. In these animals the subsequent 4-h intrarenal $\alpha$-hANP infusion then restored GFR, measured by inulin clearance, to $0.31 \pm 0.04 \mathrm{ml} / \mathrm{min}$ per $100 \mathrm{~g}(P<0.001, n=8)$, at $4 \mathrm{~h}$ compared with saline/albumin-infused control values of $0.05 \pm 0.01$ $\mathrm{ml} / \mathrm{min}$ per $100 \mathrm{~g}(n=8)$. These findings suggest that the effectiveness of $\alpha$-hANP infusion in protecting GFR after renal ischemia may depend on the intravascular volume status of the animal as well as the severity of the ischemic damage, which may be modified not only by the duration of clamping but also by the presence or absence of the contralateral kidney.

Histology. To further define and assess possible morphological correlates underlying this protective effect, we compared plastic embedded tissue sections from kidneys in uninephrectomized animals infused intrarenally for varying lengths of time with $\alpha$-hANP with sections from similarly infused saline/albumin controls. On gross examination, 2 and 4 $h$ after renal ischemia (Table I), the cut surface of the kidney showed a dark red coloration mainly of the medulla, essentially sparing the papilla. Histologically (Fig. $3 A$ ), there was severe hyperemia of peritubular capillaries in the outer medulla and innermost zone of the cortex, while the papilla and middle and outer cortex were barely affected. In those regions exhibiting the most severe hyperemia (Fig. $3 \mathrm{~B}$ ), there were numerous protein casts and incipient tubular cell shedding, while peritubular blood vessels were dilated and showed some margination of neutrophils. Thrombi were not evident, but red cells were densely packed and appeared "sticky," some being inside the lumina of collecting tubules. The middle and outer cortex did not show extensive hyperemia, but focal protein casts were apparent in a few tubules without signs of hematuria.

In contrast, after $2 \mathrm{~h}$ of $\alpha$-hANP infusion, kidneys were considerably less affected (Fig. $3 \mathrm{D}$ ), showing only a slight-tomoderate degree of hyperemia, mainly in the outer medulla. These hyperemic peritubular vessels were concentrated in the areas of highest density, around the descending loops, but there was almost no congestion in the regions occupied by collecting ducts. Some nephrons, mainly in the inner cortex and outer medulla, still contained protein casts but 4 and $24 \mathrm{~h}$ after initiating the $\alpha$-hANP infusion (Fig. $3 E$ and $F$ ) renal tissue was essentially normal (Fig. $3 C$ ). A semiquantitative analysis of the overall histological findings is presented in Table II.

Table I. Hyperemia of Kidneys as Assessed by Gross Examination of Cut Surfaces

$\begin{array}{ll}1 \mathrm{~h} \text { postclamp } & +++ \\ 2 \mathrm{~h} \text { postclamp } & +++ \\ 24 \mathrm{~h} \text { postclamp } & +++ \\ 2 \mathrm{~h} \text { of ANP } & ++ \\ 4 \mathrm{~h} \text { of ANP } & 0 \\ 24 \mathrm{~h} \text { after ANP } & 0 \\ 48 \mathrm{~h} \text { after ANP } & 0\end{array}$

Semiquantitative assessment of macroscopic appearance of cut renal surface 1, 2, and $24 \mathrm{~h}$ after $60 \mathrm{~min}$ of renal artery clamping without $\alpha$-hANP infusion (top), compared with appearance after 2 and $4 \mathrm{~h}$ of infusion (middle), or 24 and $\mathbf{4 8} \mathrm{h}$ after stopping the 4-h infusion (bottom). Grades: 0 , normal, i.e., as controls; + , slight change; ++ , moderate change; +++ , severe change. 

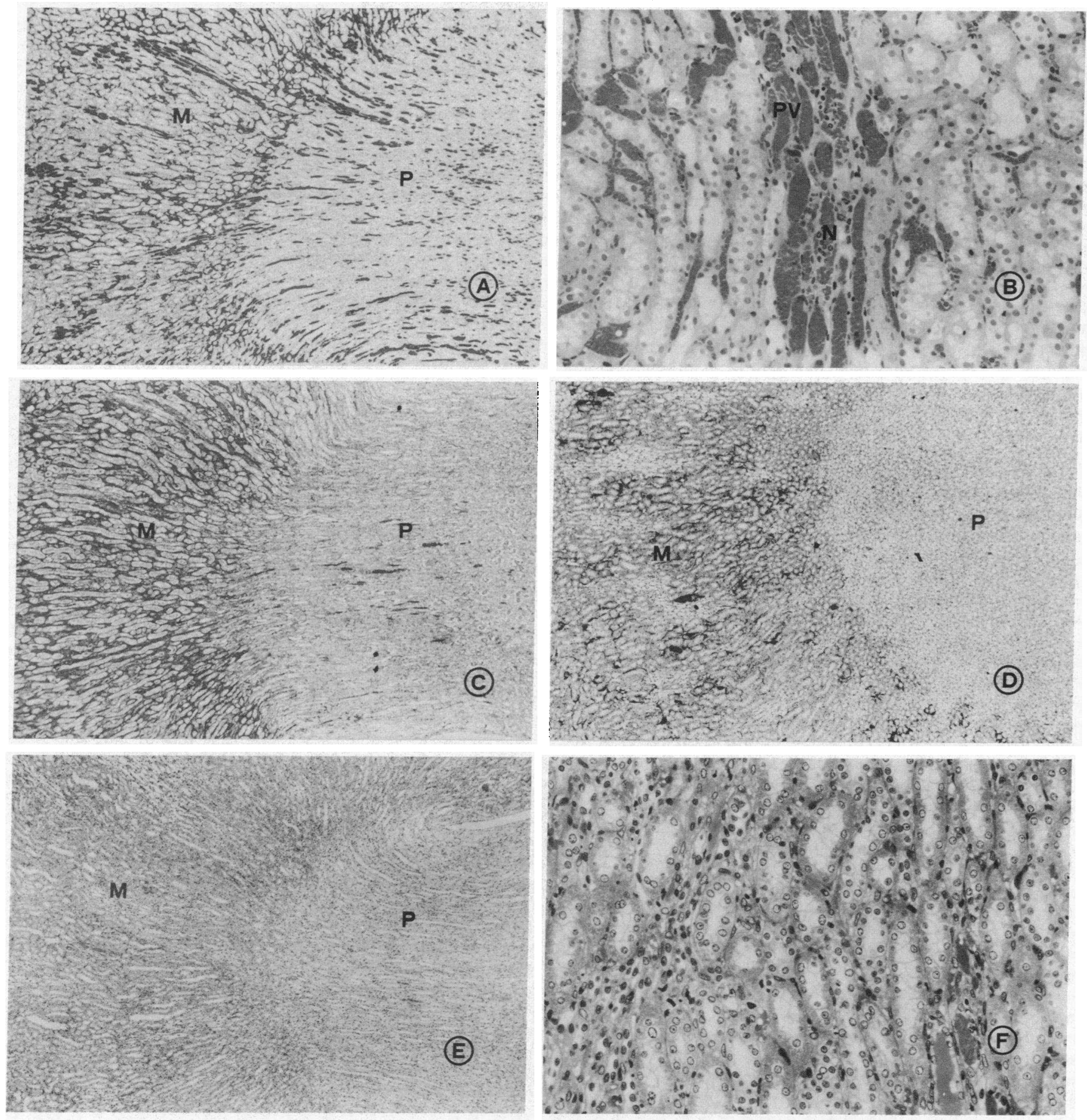

Figure 3. (A) Rat kidney $2 \mathrm{~h}$ after renal ischemia. The medulla is oriented to the left, the papilla to the right side of the panel, as in panels $C, D$, and $E$. There is severe hyperemia of peritubular capillaries in the medullary compartment, while the papillary tissue is less affected (hematoxylin-eosin stain, as in the remaining figures, $\times 12$ ). (B) $2 \mathrm{~h}$ after renal ischemia, affected part of the medulla at higher magnification. Peritubular blood vessels are dilated and, in the central part of the figure, intravascular accumulation and margination of neutrophils are seen. There are focal gaps in the nuclear lining of epithelia, indicating incipient tubular damage $(\times 140)$. (C) Normal rat renal tissue as control, showing slightly heavier staining of medullary inter-

stitial tissue ( $\times 12)$. (D) Rat kidney after $2 \mathrm{~h}$ of $\alpha$-hANP infusion. In contrast to $A$, only a slight-to-moderate degree of hyperemia of medullary tissue is observed ( $\times 12)$. (E) Rat kidney after $4 \mathrm{~h}$ of $\alpha$-hANP infusion. Note that peritubular hyperemia is no longer seen and that the structure of renal tissue is well preserved $(\times 12)$. $(F)$ Renal tissue $24 \mathrm{~h}$ after initiating the $\alpha$-hANP infusion. Medullary tissue at higher magnification, with normal epithelial lining of tubules and no signs of peritubular hyperemia. Residual protein casts are visible at the right bottom corner of the figure $(\times 90)$. $M$, medulla; $P$, papilla; $P V$, peritubular vessels; $N$, neutrophil. 


\section{Discussion}

The results show that a 4-h intrarenal infusion of $\alpha$-hANP after renal ischemia in bilaterally intact as well as uninephrectomized animals can preserve glomerular filtration rate and reduce renal tissue damage.

Although the underlying mechanisms of this protection are not clear, three major complementary properties of the peptide, viz, vasodilation, antagonism of vasoconstrictors, and ability to increase glomerular filtration may play a role (4-6). From autoradiographic studies demonstrating accumulation of radiolabeled ANP in rat glomeruli and medullary and papillary vasa recta and identification of high-affinity binding sites on rat glomerular mesangial and smooth muscle cells in culture $(11,12)$, it is likely that these protective effects occur through specific receptor-mediated actions of the peptide at multiple sites within renal tissue. Histologically, attenuation of GFR impairment in postischemic kidneys treated with $\alpha$ hANP appears to be associated with a progressive loss of hyperemia in the inner cortex and outer medulla. Previous work has indicated that this characteristic phenomenon is typical after ischemia, that it develops during the time of clamping, and that its severity is related to the degree of renal impairment and subsequent time of recovery (7). Prolonged vasoconstriction, mediated perhaps by catecholamines or angiotensin (13), has been considered as a possible underlying mechanism (14). The recent demonstration that accumulation of circulating and intrarenal vasoconstrictor catecholamines occurs during this phase and that the $4-h$ infusion of $\alpha$-hANP is associated with a marked depletion of renal tissue norepinephrine levels $(15,16)$ supports the view that antagonism of catecholaminemediated vasoconstriction may be an important aspect of the protective effect.

Additionally, tubular protein casts resulting from tubular fluid stasis, leakage of albumin from plasma, and subsequent precipitation of Tamm-Horsfall protein may also contribute to the renal impairment by producing tubular obstruction (17, 18). In this case, the increased tubular flow resulting from $\alpha$-hANP infusion may provide an additional mechanism whereby GFR is protected after ischemia. By reducing tubular fluid protein concentration, precipitation of Tamm-Horsfall protein may be avoided and renal function improved.

Although the detailed mechanisms underlying the $\alpha$ hANP-mediated enhancement of diuresis and natriuresis are as yet incompletely understood (19), several possibilities have been suggested. Hemodynamic changes such as an increase in glomerular filtration produced by dilatation of the afferent arteriole and constriction of the efferent arteriole with enhanced glomerular capillary pressure, a change in papillary peritubular Starling forces, and perhaps also a medullary redistribution of renal blood flow, seem to play an important role (20). In addition, $\alpha$-hANP may contribute to the natriuresis through direct inhibition of reabsorption along the papillary collecting duct (21), and/or reduced activity of the renal catecholamine system (22), whereas diuresis may be promoted further by inhibition of ADH-mediated tubular water permeability (23).

Whatever the explanation, it is obvious from the short 2-h $\alpha$-hANP infusion that the disappearance of medullary hyperemia and protein casts is not an instantaneous process and that some time is needed for them to be completely eliminated. This indicates that the severity of the ischemic insult, the length of time of $\alpha$-hANP infusion and the total dose administered may be important factors determining the speed and extent of recovery. Also, because part of the protective effect may also rely on the maintenance of an enhanced urine flow for a sufficient length of time to allow protein casts to be completely washed from the tubules, factors that decrease renal blood flow and GFR may be expected to delay recovery. Presumably for this reason short-term systemic infusion of $\alpha$-hANP $(1-2 \mu \mathrm{g} / \mathrm{kg}$ per min over $1 \mathrm{~h})$ is ineffective in restoring renal function after ischemia because the inability to achieve therapeutically effective intrarenal concentrations of $\alpha$-hANP without producing marked decreases in mean arterial pressure, and hence GFR and renal blood flow, precludes the prolonged maintenance of an enhanced tubular flow or alleviation of medullary hyperemia. Thus, in hypotension, blood pressure would probably need to be restored to the normal range before beneficial effects became apparent.

In summary, the overall effectiveness of $\alpha$-hANP in reducing renal impairment after ischemia is probably due to its combined pharmacological profile of actions. This idea is supported by observations that treatments which produce only vasodilatation, diuresis, or vasoconstrictor antagonism (24) do not improve renal function after ischemia. Therefore, whereas the physiological roles of $\alpha$-hANP in the regulation of body fluid and electrolyte balance under normal conditions remain to be defined, its novel pharmacological actions may enhance

Table II. Histological Assessment of Lesions: X 'Events' per Y High-power Fields

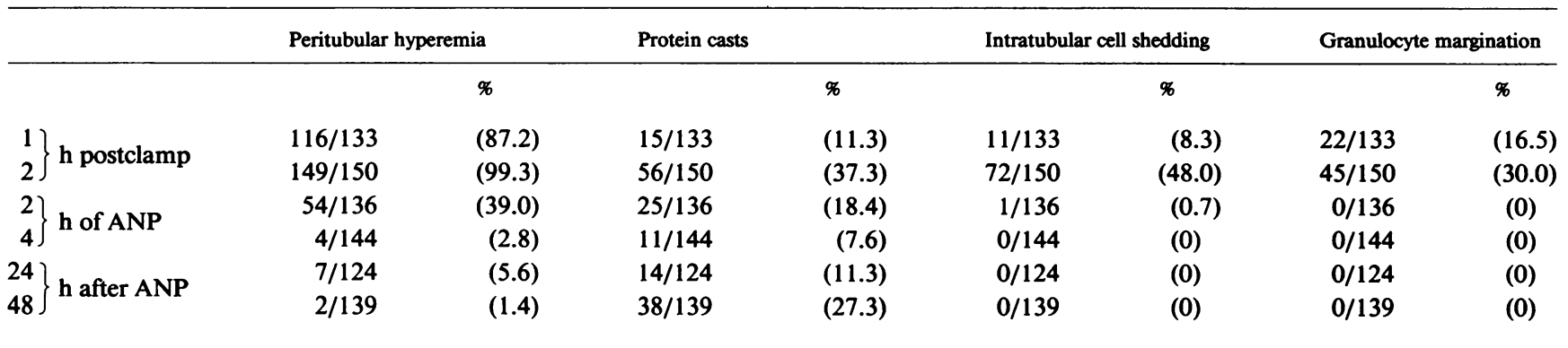

Assessment of major alterations in kidney structure at 1 or $2 \mathrm{~h}$ after $60 \mathrm{~min}$ of renal artery clamping without $\alpha$-hANP infusion (top), after 2 and $4 \mathrm{~h}$ of infusion (middle), or 24 and $48 \mathrm{~h}$ after stopping the 4-h infusion (bottom). Figures indicate the fraction and percentage of total microscopic high-power fields, analyzed in hematoxylin-eosin stained sections, which showed peritubular hyperemia, protein casts, cell shedding, or granulocyte margination. 
the understanding of the pathology and treatment of ischemia-induced ARF and perhaps lead to an effective means of prevention.

\section{Acknowledgments}

The authors would like to thank the Swiss National Science Foundation and the Ciba Geigy Corporation, Basle, Switzerland, for their financial support, and R. Takkinen, J. Boden, and G. Haueter for their patience and excellent technical assistance in the experiments.

\section{References}

1. Stott, R. B., J. S. Cameron, C. S. Ogg, and M. Bewick. 1972. Why the persistently high mortality in acute renal failure? Lancet. ii:75-79.

2. Misono, K. S., R. T. Grammer, H. Fukumi, and T. Inagami. 1984. Rat atrial natriuretic factor: isolation, structure and biological activities of four major peptides. Biochem. Biophys. Res. Commun. 123:444-451.

3. Kanagawa, K., A. Fukuda, I. Kubota, Y. Hayashi, and H. Matusuo. 1984. Identification in rat atrial tissue of multiple forms of natriuretic polypeptides of about 3,000 daltons. Biochem. Biophys. Res. Commun. 121:585-591.

4. Needleman, P., S. P. Adams, B. R. Cole, M. G. Currie, D. M. Geller, M. L. Michener, C. B. Saper, D. Schwartz, and D. G. Standaert. 1985. Atriopeptins as cardiac hormones. Hypertension. 7:469-482.

5. Maack, T., M. J. F. Camargo, H. D. Kleinert, J. H. Laragh, and S. A. Atlas. 1985. Atrial natriuretic factor: structure and functional properties. Kidney Int. 27:607-615.

6. Ackermann, U. 1986. Structure and function of atrial natriuretic peptides. Clin. Chem. 32:241-247.

7. Mason, J., J. Torhorst, and J. Welsch. 1984. Role of the medullary perfusion defect in the pathogenesis of ischemic renal failure. Kidney Int. 26:283-293.

8. Burke, T. J., and R. W. Schrier. 1983. Ischemic acute renal failure: pathogenic steps leading to acute tubular necrosis. Circu. Shock. 2:255-259.

9. Tanner, G. A., K. L. Sloan, and S. Sophasan. 1973. Effects of renal artery occlusion on kidney function in the rat. Kidney Int. 4:377-389.

10. Shemesh, O., H. Golbetz, J. Kriss, and B. Myers. 1985. Limitations of creatinine as a filtration marker in glomerulopathic patients. Kidney Int. 28:830-838.

11. Ballermann, B. J., R. L. Hoover, M. J. Karnovsky, and B. M.
Brenner. 1985. Physiologic regulation of atrial natriuretic peptide receptors in rat renal glomeruli. J. Clin. Invest. 76:2049-2056.

12. Hirata, Y., M. Tomita, H. Yoshimi, and M. Ikeda. 1984. Specific receptors for atrial natriuretic factor (ANF) in cultured vascular smooth muscle cells of rat aorta. Biochem. Biophys. Res. Commun. 125:562-568.

13. Yared, A., V. Kon, and I. Ichikawa. 1985. Mechanism of preservation of glomerular perfusion and filtration during acute extracellular fluid volume depletion. J. Clin. Invest. 75:1477-1487.

14. Mason, J., J. Welsch, and T. Takabatake. 1983. Disparity between surface and deep nephron function early after renal ischemia. Kidney Int. 24:27-36.

15. Shaw, S. G., and P. Weidmann. 1986. Catecholamines in experimental ischemic renal failure. Kidney Int. 29:310.

16. Shaw, S. G., P. Weidmann, and J. Hodler. 1987. Atrial natriuretic peptide effects on renal tissue catecholamines following renal ischemia. In Proceedings of the 2 nd World Congress on Biologically Active Atrial Peptides. New York. 192.

17. Kant, K. S., A. J. Besce, D. M. Clyne, and V. E. Pollak. 1977 Co-precipitation of Tamm-Horsfall protein with myoglobin, haemoglobin, Bence Jones protein and albumin. Effect of pH. Clin. Res. 25:594A.

18. Thiel, G., D. De Rougement, J. Torhorst, A. Kaufmann, L. Peters-Haefeli, and F. P. Brunner. 1980. Importance of tubular obstruction and its prevention in ischemic acute renal failure in the rat. In Renal Pathophysiology. Recent Advances. A. Leaf, G. Giebisch, L. Bolis, S. Gorini, editors. Raven Press, New York. 223-238.

19. Weidmann, P., L. Hasler, M. P. Gnädinger, R. E. Lang, D. E. Uehlinger, S. Shaw, W. Rascher, and F. C. Reubi. 1986. Blood levels and renal effects of atrial natriuretic peptide in normal man. J. Clin. Invest. 77:734-742.

20. Ballermann, B. J., and B. M. Brenner. 1985. Biologically active atrial peptides. J. Clin. Invest. 76:2041-2048.

21. Sonnenberg, H., W. A. Cupples, A. J. De Bold, and A. T. Veress. 1982. Intrarenal localization of the natriuretic effect of cardiac atrial extract. Can. J. Physiol. Pharmacol. 60:1149-1152.

22. Debinski, W., O. Kuchel, R. Garcia, N. T. Buu, K. Racz, M. Cantin, and J. Genest. 1986. Atrial natriuretic factor inhibits the sympathetic nervous activity in one-kidney, one-clip hypertension in the rat. Proc. Soc. Exp. Biol. Med. 181:173-177.

23. Samson, W. K., and J. C. Vanatta. 1986. Atrial natriuretic factor inhibits vasotocin-induced water reabsorption in the toad urinary bladder. Proc. Soc. Exp. Biol. Med. 181:169-172.

24. Reubi, F. C., and C. Vorburger. 1976. Hemodynamics and pathophysiology of acute renal failure after shock in man. Kidney Int. 10:5137-5143. 